\title{
Power system operation considering detailed modelling of the natural gas supply network
}

\author{
Ricardo Moreno ${ }^{1}$, Diego Larrahondo ${ }^{2}$, Oscar Florez ${ }^{3}$ \\ ${ }^{1,2}$ Universidad Autónoma de Occidente, Cali, Colombia \\ ${ }^{3}$ Universidad Distrital Francisco José de Caldas, Colombia
}

\section{Article Info \\ Article history: \\ Received May 11, 2020 \\ Revised May 25, 2021 \\ Accepted Jun 12, 2021 \\ Keywords: \\ Natural gas system Optimal power flow Power systems Renewable energy Wind power}

\begin{abstract}
The energy transition from fossil-fuel generators to renewable energies represents a paramount challenge. This is mainly due to the uncertainty and unpredictability associated with renewable resources. A greater flexibility is requested for power system operation to fulfill demand requirements considering security and economic restrictions. In particular, the use of gas-fired generators has increased to enhance system flexibility in response to the integration of renewable energy sources. This paper provides a comprehensive formulation for modeling a natural gas supply network to provide gas for thermal generators, considering the use of wind power sources for the operation of the electrical system over a 24-hour period. The results indicate the requirements of gas with different wind power level of integration. The model is evaluated on a network of 20 NG nodes and on a 24-bus IEEE RTS system with various operative settings during a 24-hour period.
\end{abstract}

Corresponding Author:

Ricardo Moreno

Energy and Mechanical Department

Universidad Autónoma de Occidente

Cali, Colombia

Email: rmoreno@uao.edu.co,odflorez@udistrital.edu.co

\section{INTRODUCTION}

Two crucial sectors for life nowadays are natural gas (NG) and electricity. Although these sectors followed different paths throughout the majority of the 20th century, in the last 25 years they have progressively converged. The usage of NG for electricity generation through gas-fired generation plants has enhanced the interdependence among gas and electric power sources [1]. Consequently, the gas and power systems have become intertwined, leading to new challenges due to the complexity involved in the issues that each poses to the other [2].

In terms of gas-fired power plants, limitations due to both gas supply contracts and access to the gas network are unknown, generating effects and externalities in their operation. From the gas system perspective, the demand for natural gas from residential and industrial areas is more predictable and less volatile, compared to the natural gas consumption for electricity generation. For these reasons, the gas system interconnected to the electrical system requires greater flexibility. Nevertheless, flexibility is expensive because it requires additional extraction and transmission capacities to provide the necessary operational margin [3].

Moreover, reducing greenhouse gas emissions is imperative for climate change mitigation, leading to increased investments in reducing conventional fossil fuel-based power generation [4]-[6]. Therefore, a massive effort has been made worldwide to integrate renewable energy technologies [7]. This implementation 
has largely been done through photovoltaic and wind systems [8]. Despite this, the use of these resources can influence the electric power system operation due to certain characteristics of these resources such as uncertainty and variability [9]. Generating new requirements for dealing with disruptions, i.e. challenges in stability [10]. Therefore, energy systems require strategies to improve their flexibility and stability, and thus achieve the integration of these intermittent resources and meeting the requirements of the demand [11], [12].

One of the technologies currently used, to balance intermittency and increase system flexibility, is gasfired thermal generators [13]. This is because they have technical requirements, such as shorter on/off times, greater up and down ramps, lower emissions and higher financial performance in comparison with traditional coal-fired power plants [14]. Despite this, the flexibility they can bring to the system is limited and requires greater flexibility of the gas system [3].

Consequently, this paper provides a comprehensive formulation for modeling a NG supply network to provide gas for thermal generators, considering the use of wind power sources for the operation of the electrical system over a 24-hour period. Integrated NG and electricity system's target functionality is to minimize the overall cost of the system, taking into account power generation costs, gas costs and losses in both systems. The resulting formulation provides optimum results regarding all generators, gas consumption requirements and technical requirements of the gas-fired generators, all under various operating states and scenarios.

This paper is structured in these sections: Section 2 presents the problem description and formulation. In section 3, the electrical and gas systems and their parameters are outlined. Then, using the described systems, the formulation is tested. The results are analyzed and discussed at the end of this section. Some concluding remarks on this topic are given in section 4.

Electric power systems and gas systems have been extensively studied from different points of view. The first have been analyzed, through the optimal energy flow for the dispatch of the generation resources [15][17]. As a result, the formulation of the multi-period DC optimal power flow (DCOPF) has been enhanced in order to incorporate renewable energy generation's variability, considering factors such as electricity demand and wind availability uncertainty [18]-[21].

On the other hand, the gas system has been analyzed through different studies. In one of them, a detailed study of gas transmission was made, implementing a simplex algorithm expansion [22]. Martin et al. [23], a fully intermixed model was applied for the gas network optimization steady-state case. Pfetsch et al. [24] investigate several approaches in order to resolve a main challenge in pipeline gas transmission, which is the nomination validation problem, through different algorithms based on linear and nonlinear mixed-integral methods.

The interdependence of electricity and NG systems has been extensively studied. Zhang et al. [25], in order to simulate the coordinated stochastic model for the economic response of the hourly power system demand, along with the NG transport constraints, a Monte-Carlo simulation was applied. Operational performance of hydrothermal systems and the NG network in the short term was studied at [26]. Because of the necessity of gas-fired power plants, the transport of NG through pipelines affects power generation and transmission with respect to safety and economics, a situation that was studied in [27]. And the reference [28] used the Newton-Raphson formulation to analyze integrated electricity and NG systems.

In addition, considerable research has been done on the coordination of natural gas and electricity systems. Qadrdan et al. [29]-[31] investigated how the increase in wind power plants impacts on the British gas network. Sohrabi et al. [32], performed steady-state integrated NG transmission network and power system formulation, taking into account the market price of electricity on the basis of the information gap decision theory. The impact of NG system on the short-term planning of the electricity system considering a considerable increase of renewable energies is presented in [33]. An operational strategy based on interval optimization for integrated gas and electricity systems is proposed in [34] to enhance system performance considering demand response and renewable energy sources uncertainty. 


\section{PROBLEM FORMULATION}

\subsection{Notation}

\subsubsection{Indices}

$\begin{array}{ll}g & \text { Index of thermal units of generation. } \\ i, j & \text { Index of network buses connected by transmission branches. } \\ m, n & \text { Index of gas buses connected by a line pipe. } \\ t & \text { Index of time periods (hour). }\end{array}$

\subsubsection{Parameters}

\begin{tabular}{|c|c|}
\hline$A_{i}$ & Wind turbine power connected to bus $i$ (MW). \\
\hline$w_{i, t}$ & Available wind for the turbine connected to bus $i$ at time $t$ \\
\hline$C_{m, n}$ & Constant of the gas line pipe connecting node $m$ to $n$. \\
\hline$L_{i, t}$ & Electric load in bus $i$ at time $t$. \\
\hline$b_{g}$ & Thermal unit fuel cost ratio. \\
\hline$P_{g}^{\max }, P_{g}^{\min }$ & Maximum/Minimum power generation limits for thermal units. \\
\hline$P_{i j}^{\max }$ & Maximum power flow limits of branch connecting bus $i$ to $j$. \\
\hline$x_{i j}$ & Reactance of branch connecting bus $i$ to $j$. \\
\hline$r_{i j}$ & Resistance of branch connecting bus $i$ to $j$. \\
\hline$\eta$ & Efficiency of thermal units. \\
\hline$k_{t}$ & Gas demand percentage at time $t$. \\
\hline$R_{g}^{u p}, R_{g}^{\text {down }}$ & Ramp-up/down limits of thermal generation unit $g(\mathrm{MW} / \mathrm{h})$. \\
\hline$S g_{n}^{\max }, S g_{n}^{\min }$ & Maximum/Minimum gas supply limits at node $n$. \\
\hline$S d_{n}$ & Gas demand in node $n(\mathrm{Scm})$. \\
\hline $\operatorname{Pr}_{n}^{\max }, \operatorname{Pr}_{n}^{\min }$ & Maximum/Minimum gas pressure limits at node $n$. \\
\hline VOOL & Load loss value ( $\$ / \mathrm{MWh})$. \\
\hline$V W C$ & Wind loss value (\$/MWh). \\
\hline$H$ & Conversion value (MBtu $\left./ 10^{6} \mathrm{Scm}\right)$. \\
\hline
\end{tabular}

\subsubsection{Variables}

$P_{i j, t} \quad$ Active power flow of branch connecting bus $i$ to $j$ at time $t$ (MW).

$P_{g, t} \quad$ Active power produced by thermal unit $g$ at time $t$ (MW).

$P_{i, t}^{w} \quad$ Active power generated by wind turbine connected to bus $i$ at time $t$ (MW).

$P_{i, t}^{w c} \quad$ Constrained wind turbine power connected to bus $i$ at time $t$ (MW).

$f_{m, n, t} \quad$ Gas flow from node $m$ to node $n$ at time $t(\mathrm{Scm})$.

$L S_{i, t} \quad$ Load shedding in bus $i$ at time $t(\mathrm{MW})$.

$\operatorname{Pr}_{n, t} \quad$ Gas pressure at node $n$ time $t$ (bar).

$S g_{n, t} \quad$ Gas supply in node $n$ time $t$ (Scm).

$S e_{n, t} \quad$ Gas demand in node $n$ time $t$ for generation of thermal units $(\mathrm{Scm})$.

$E C \quad$ 24-hour electrical operating costs (\$).

$G C \quad$ 24-hour gas operating costs (\$).

$O F \quad$ 24-hour Total operating costs (\$).

$\theta_{i, t} \quad$ Voltage angle of bus $i$ at time $t(\mathrm{rad})$.

\subsection{Formulation}

This formulation is based on an optimization problem, designed to determine the lowest overall system operating cost, derived from the production of electricity to meet demand over a 24-hour period, including all gas system costs as specified in (1).

$$
O F=E C+G C
$$

The (2) shows the total cost of electricity generation for a 24-hour period. Through the sum of the cost of producing energy with $g$ thermal units during a $t$ time interval, plus the costs associated with load loss, plus the costs associated with non-utilization of the maximum wind generation source available. 


$$
E C=\sum_{g, t} b_{g} \cdot P_{g}+\sum_{i, t}\left(V O L L \cdot L S_{i, t}+V W C \cdot P_{i, t}^{w c}\right)
$$

Dispatch model constraints are determined by the optimal power flow equations. The DC optimal power flow equilibrium is defined by (3). The amount of power flowing in each line is determined by (4). The constraints on the maximum amount of power that can flow through each line are given by the (5).

$$
\begin{gathered}
\sum_{g} P_{g, t}+L S_{i, t}+P_{i, t}^{w}-L_{i, t}=\sum_{j} P_{i j, t} \\
P_{i j, t}=\frac{1}{X_{i j}}\left(\theta_{i, t}-\theta_{j, t}\right) \\
-P_{i j, t}^{\max } \leq P_{i j, t} \leq P_{i j, t}^{\max }
\end{gathered}
$$

On the other hand, the restrictions for thermal generation units are defined in (6), (7), and (8), where (6) corresponds to the operational range of thermal generators. The (7) and (8) specify the maximum limits of the ramp-up and ramp-down of thermal generators, i.e. the maximum value that can vary the power of a generator in a one-hour interval.

$$
\begin{gathered}
P_{g, t}^{\min } \leq P_{g, t} \leq P_{g, t}^{\max } \\
P_{g, t}-P_{g, t-1} \leq R_{g}^{u p} \\
P_{g, t-1}-P_{g, t} \leq R_{g}^{\text {down }}
\end{gathered}
$$

The load shedding of bus $i$ is restricted to the existing demand at time $t$ as indicated in (9).

$$
0 \leq L S_{i, t} \leq L_{i, t}
$$

The constraints for wind generation are defined in (10) and (11), where (10) corresponds to to the amount of available wind power not utilized. In (11) indicates the range of minimum and maximum power that a wind turbine can produce, taking into account the capacity variables and wind availability.

$$
\begin{gathered}
P_{i, t}^{w c}=w_{t} \cdot A_{i}-P_{i, t}^{w} \\
0 \leq P_{i, t}^{w} \leq w_{t} \cdot A_{i}
\end{gathered}
$$

The (12) indicates the total cost to supply gas considering the purchase price of gas delivered at node $n$ during an interval of time $t$.

$$
G C=\sum_{n, t} c_{n} \cdot S g_{n, t} \cdot H
$$

The flow conservation equation at node $n$, insures the gas balance at node $n$ and is given by the (13).

$$
\sum_{m} f_{n, m, t}=\sum_{m} f_{m, n, t}+S g_{n, t}-k_{t} \cdot S d_{n}-S e_{n, t}
$$

Now, is up to consider the constraints on the gas transportation tubes. In this case, there's no distinction between passive and active gas transportation tubes. For the gas transportation tube, the relation between the flow $f_{m, n, t}$ in the gas transportation tube $(m, n)$ and the pressures $P r_{m, t}$ and $P r_{n, t}$ is given by the (14). 
Where $C_{m, n}$ is a value that varies according to length, diameter and absolute roughness of the pipeline and gas composition.

$$
f_{m, n, t}^{2}=C_{m, n}^{2} \cdot\left(\operatorname{Pr}_{m, t}^{2}-\operatorname{Pr}_{n, t}^{2}\right)
$$

Alternately, the restrictions for gas units are defined in (15), and (16), where (15) corresponds to the limitations of gas inflow at a supply node $n$. In the case of gas pressure restrictions, natural gas transportation companies must not receive natural gas at a higher pressure than that guaranteed by the supplier at the input point. On the contrary, the demand at each exit point must be satisfied at a minimum pressure secured to the industrial user or the local distribution company, this is expressed in (16).

$$
\begin{aligned}
& S g_{n}^{\min } \leq P g_{n, t} \leq S g_{n}^{\max } \\
& \operatorname{Pr}_{n}^{\min } \leq \operatorname{Pr}_{n, t} \leq \operatorname{Pr}_{n}^{\max }
\end{aligned}
$$

Finally, gas-fired power plants connect the electricity and natural gas systems. Since gas fired power plants produce energy for the electric system as a supplier, and at the same time, they consume natural gas, making it a requirement for the natural gas system. This is expressed in the (17).

$$
b_{g} \cdot P_{g}=S e_{n, t} \cdot H \cdot \eta \quad \in \quad N
$$

\section{RESULTS AND DISCUSSION}

With the objective of quantify the requirements of gas according to wind integration, a power system case is used to simulate operational conditions with a detailed modeling of the gas network. In this section different scenarios are evaluated, with a 24 hour period to consider the dispatching of generators. All simulations were completed by a personal computer (PC) using Ipopt ${ }^{\circledR}$ Solver (3.12.10) under the JuMP 0.19.2 Julia platform [35].

\subsection{Case description: IEEE 24-bus and gas network 20-stations}

This section presents the results and simulations on the gas needs in the energy transition considering the integration of wind energy. This is based on the gas network linkage with electricity network, shown in Figure 1. Also, considering different demand cases, wind availability profiles, and installed wind capacities.

The gas network linkage with electricity network, is composed for a modified IEEE 24-bus power system and the gas network of Belgium, modified from [15], [22]. The data for thermal units are listed in Table 1, modify from [15]. In Table 2 the lines reactance, power line constraints and interconnections are shown, modify from [15]. NG system nodes' technical and economic features are shown in Table 3, and the operational specifications of gas network are provided in Table 4, modifying the information from [15], [22].

\subsection{Results}

The system performance was evaluated on the basis of an increase in wind power generation capacity, starting with a case without wind power installed (i.e. $0 \mathrm{MW}$ ), then a case with an installed capacity of $500 \mathrm{MW}$ and a case of $1000 \mathrm{MW}$. The analysis highlights the changes in gas requirements for power generation during a 24-hour period due to wind availability. The gas requirements according to wind power generation over a 24-hour period are shown in Figure 2. It can be seen that the gas requirements in the case without wind power available have a similar performance in all the simulations. Conversely, when having an installed wind power (i.e. $500 \mathrm{MW}$ ), the gas requirements present a greater variability, which grows when facing different wind patterns as the installed wind power increases (i.e. $1000 \mathrm{MW}$ ).

As installed wind power increases, in some cases, peak gas requirements also rise. These peaks may be more noticeable in cases with high variability in the wind profile, like the one presented in Figure 2(b). At hour 11 in the case with $0 \mathrm{MW}$ of installed wind capacity, there is a requirement of gas $41130 \mathrm{Scm}$, in the cases of $500 \mathrm{MW}$ and $1000 \mathrm{MW}$ of installed wind capacity, the gas requirements increase by $100 \%$ and $315 \%$ respectively. Also in Figure 2(b), it can be seen that when there is a decrease in the gas requirement, the decrease is more considerable, as the installed wind capacity increases, as can be seen in the 16th hour. 


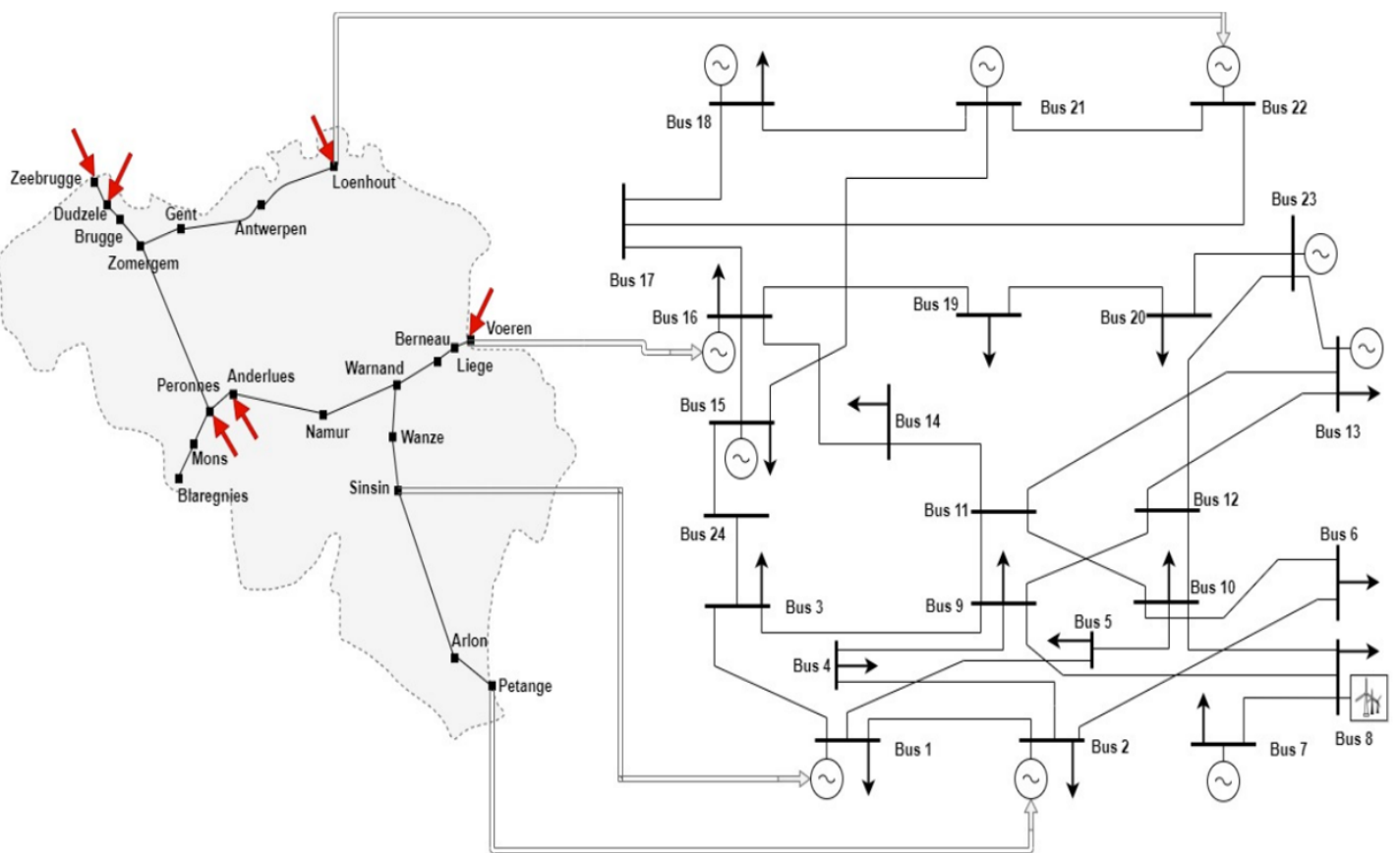

Figure 1. Gas network linkage with electricity network

Table 1. Thermal generation data for the 24-bus test system

\begin{tabular}{ccccccc}
\hline Gen & Bus & $P_{g}^{\text {min }}(\mathrm{MW})$ & $P_{g}^{\max }(\mathrm{MW})$ & Marginal Cost $(\mathrm{MW})$ & $R_{g}^{u p}(\mathrm{MW} / \mathrm{h})$ & $R_{g}^{\text {down }}(\mathrm{MW} / \mathrm{h})$ \\
\hline 1 & 18 & 100 & 400 & 5.47 & 17 & 17 \\
2 & 21 & 100 & 400 & 5.49 & 17 & 17 \\
3 & 1 & 30.4 & 152 & 23.32 & 84 & 84 \\
4 & 2 & 30.4 & 152 & 23.32 & 84 & 21 \\
5 & 15 & 54.25 & 155 & 16 & 21 & 21 \\
6 & 16 & 54.25 & 155 & 10.52 & 21 & 21 \\
7 & 23 & 108.5 & 310 & 10.52 & 21 & 28 \\
8 & 23 & 140 & 350 & 10.89 & 28 & 49 \\
9 & 7 & 75 & 350 & 20.7 & 49 & 7 \\
10 & 13 & 206.85 & 591 & 20.93 & 21 & 7 \\
11 & 15 & 12 & 60 & 26.11 & 100 & 100 \\
12 & 22 & 0 & 300 & 30 & &
\end{tabular}

Table 2. Branch data for the 24-bus test system

\begin{tabular}{cccccccc}
\hline From & To & $X_{i j}(\mathrm{p} . \mathrm{u})$ & Rating (MVA) & From & To & $X_{i j}(\mathrm{p} . \mathrm{u})$ & Rating (MVA) \\
\hline 1 & 2 & 0.0139 & 175 & 11 & 13 & 0.0476 & 500 \\
1 & 3 & 0.2112 & 175 & 11 & 14 & 0.0418 & 500 \\
1 & 5 & 0.0845 & 175 & 12 & 13 & 0.0476 & 500 \\
2 & 4 & 0.1267 & 175 & 12 & 23 & 0.0966 & 500 \\
2 & 6 & 0.192 & 175 & 13 & 23 & 0.0865 & 500 \\
3 & 9 & 0.119 & 175 & 14 & 16 & 0.0389 & 500 \\
3 & 24 & 0.0839 & 400 & 15 & 16 & 0.0173 & 500 \\
4 & 9 & 0.1037 & 175 & 15 & 21 & 0.0245 & 1000 \\
5 & 10 & 0.0883 & 175 & 15 & 24 & 0.0519 & 500 \\
6 & 10 & 0.0605 & 175 & 16 & 17 & 0.0259 & 500 \\
7 & 8 & 0.0614 & 175 & 16 & 19 & 0.0231 & 500 \\
8 & 9 & 0.1651 & 175 & 17 & 18 & 0.0144 & 500 \\
8 & 10 & 0.1651 & 175 & 17 & 22 & 0.1053 & 500 \\
9 & 11 & 0.0839 & 400 & 18 & 21 & 0.013 & 1000 \\
9 & 12 & 0.0839 & 400 & 19 & 20 & 0.0198 & 1000 \\
10 & 11 & 0.0839 & 400 & 20 & 23 & 0.0108 & 1000 \\
10 & 12 & 0.0839 & 400 & 21 & 22 & 0.0678 & 500 \\
\hline
\end{tabular}


Table 3. Technical and economical characteristics of gas nodes

\begin{tabular}{ccccccc}
\hline Gas Node & $S g_{n}^{\text {min }}(\mathrm{Scm})$ & $S g_{n}^{\text {max }}(\mathrm{Scm})$ & $S d_{n}(\mathrm{Scm})$ & $P r_{n}^{\text {min }}(\mathrm{Scm})$ & $P r_{n}^{\text {max }}(\mathrm{Scm})$ & $C_{n}(\mathrm{USD} / \mathrm{MBTU})$ \\
\hline Anderlues & 0 & 1.20 & 0.00 & 0.00 & 66.2 & 0.00 \\
Antwerpen & 0 & 0.00 & 4.03 & 1.25 & 80.0 & 0.00 \\
Arlon & 0 & 0.00 & 0.22 & 0.00 & 66.2 & 0.00 \\
Berneau & 0 & 0.00 & 0.00 & 0.00 & 66.2 & 0.00 \\
Blaregnies & 0 & 0.00 & 15.62 & 2.08 & 66.2 & 0.00 \\
Brugge & 0 & 0.00 & 3.92 & 1.25 & 80.0 & 0.00 \\
Dudzele & 0 & 8.40 & 0.00 & 0.00 & 77.0 & 2.28 \\
Gent & 0 & 0.00 & 5.26 & 1.25 & 80.0 & 0.00 \\
Liege & 0 & 0.00 & 6.39 & 1.25 & 66.2 & 0.00 \\
Loenhout & 0 & 4.80 & 0.00 & 0.00 & 77.0 & 2.28 \\
Mons & 0 & 0.00 & 6.85 & 0.00 & 66.2 & 0.00 \\
Namur & 0 & 0.00 & 2.12 & 0.00 & 66.2 & 0.00 \\
Petange & 0 & 0.00 & 1.92 & 1.04 & 66.2 & 0.00 \\
Peronnes & 0 & 0.96 & 0.00 & 0.00 & 66.2 & 1.68 \\
Sinsin & 0 & 0.00 & 0.00 & 0.00 & 63.0 & 0.00 \\
Voeren & 0 & 22.01 & 0.00 & 2.08 & 66.2 & 0.68 \\
Wanze & 0 & 0.00 & 0.00 & 0.00 & 66.2 & 0.00 \\
Warland & 0 & 0.00 & 0.00 & 0.00 & 66.2 & 0.00 \\
Zeebrugge & 0 & 11.59 & 0.00 & 0.00 & 77.0 & 80.0 \\
Arlon & 0 & 0.00 & 0.00 & 0.00 & 0.00
\end{tabular}

Table 4. Technical characteristics of gas network

\begin{tabular}{cccccccc}
\hline From & To & Active & $C_{m, n}^{2}$ & From & To & Active & $C_{m, n}^{2}$ \\
\hline Zeebrugge & Dudzele & 0 & 9.07027 & Berneau & Liege & 0 & 0.02701 \\
Zeebrugge & Dudzele & 0 & 9.07027 & Liege & Warnand & 0 & 1.45124 \\
Dudzele & Brugge & 0 & 6.04685 & Liege & Warnand & 0 & 0.02161 \\
Dudzele & Brugge & 0 & 6.04685 & Warnand & Namur & 0 & 0.86384 \\
Brugge & Zomergem & 0 & 1.39543 & Namur & Anderlues & 0 & 0.90703 \\
Loenhout & Antperwen & 0 & 0.10025 & Anderlues & Peronnes & 0 & 7.25622 \\
Antperwen & Gent & 0 & 0.14865 & Peronnes & Mons & 0 & 3.62811 \\
Gent & Zomergem & 0 & 0.22689 & Mons & Blaregnies & 0 & 1.45124 \\
Zomergem & Peronnes & 0 & 0.65965 & Warnand & Wanze & 0 & 0.05144 \\
Voeren & Berneau & 1 & 7.25622 & Wanze & Sinsin & 1 & 0.00642 \\
Voeren & Berneau & 1 & 0.10803 & Sinsin & Arlon & 0 & 0.00170 \\
Berneau & Liege & 0 & 1.81405 & Arlon & Petange & 0 & 0.02782 \\
\hline
\end{tabular}

Similar to peak gas requirements, as wind capacity increases, so can overall gas consumption in a 24-hour period. This can be seen in Figure 2(d), in which gas consumption for the case of $500 \mathrm{MW}$ of installed wind capacity is higher in almost every hour over the case without wind capacity. As well as the gas requirements are greater according with the increase in wind power capacity. Nevertheless, there may be cases in which increasing the wind capacity generates a decrease in gas consumption in a few hours, as shown in Figure 2(c). This is why gas consumption was evaluated for a period of 192 hours, equivalent to 8 days, for different installed wind capacity, starting from $0 \mathrm{MW}$ to $1100 \mathrm{MW}$, in periods of $100 \mathrm{MW}$, as shown in Figure 3.

These results depend directly on the technical and economic requirements of the thermal generators, present in Table 1, and the economic requirements of the gas, present in Table 3. This is because, in this case, the cost of natural gas used for power generation is higher than the average cost of thermal generators that are not gas-fired. This generates that when solving the optimal flow of power and the economic dispatch, it looks for to use in a minimum way the gas, and therefore the gas-fired generators. However, due to the technical limitations of some thermal generators, in particular their reduced rate of power change per hour, it is necessary to use gas-fired thermals, to supply the variations present in the power system.

Variations in the power system as mentioned above increase when implementing wind systems. This is due to the fact that in the search to use wind energy in totality, there are some fluctuations in the power generation of the electrical system, which must be controlled by the other generation plants, in order to have an optimal power flow. These fluctuations in power generation grow proportionally as the installed wind capacity increases. Given the limited ramps of coal-fired power plants, variations must be controlled by gas-fired power 
plants, which leads to increased gas consumption. And as the fluctuations grow, due to the increase in installed wind capacity, so does gas consumption, as shown in Figure 3.

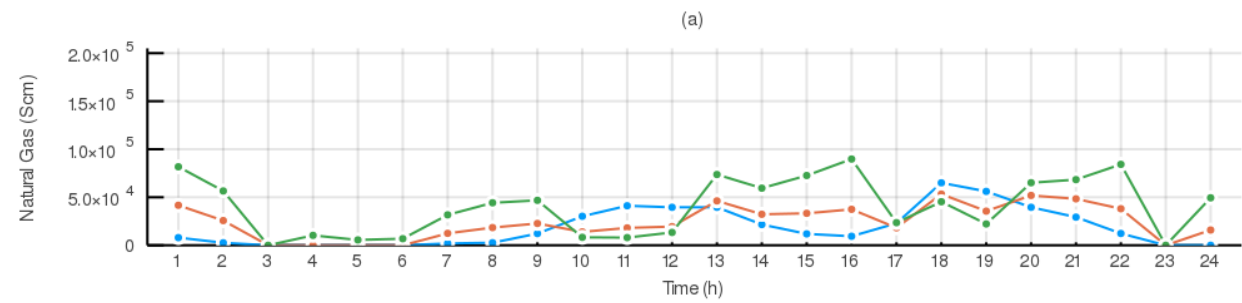

(b)
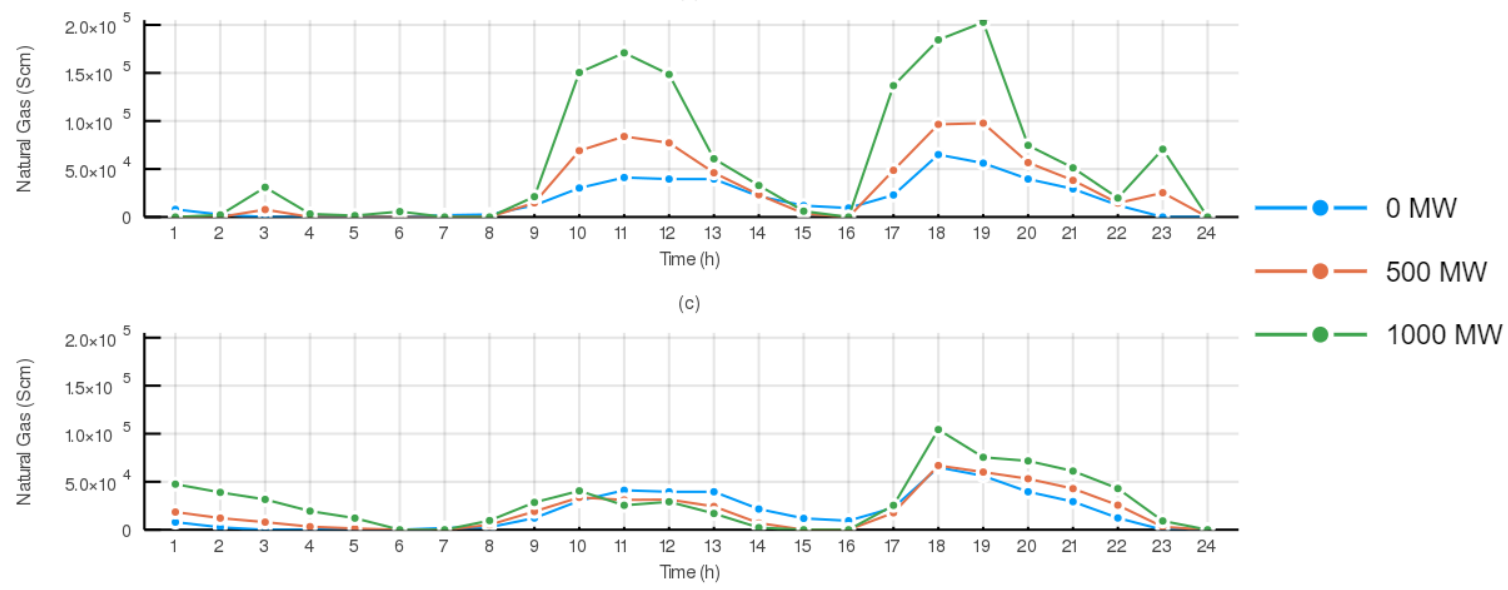

(d)

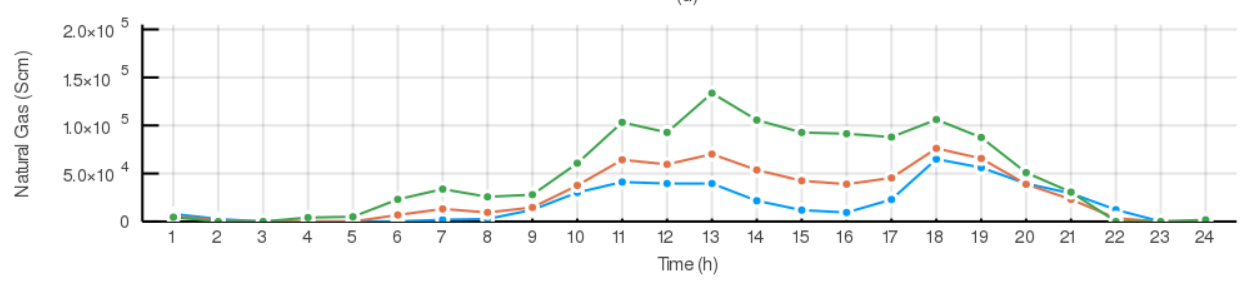

Figure 2. Hourly gas requirements for installed wind power capacities within a 24-hour period

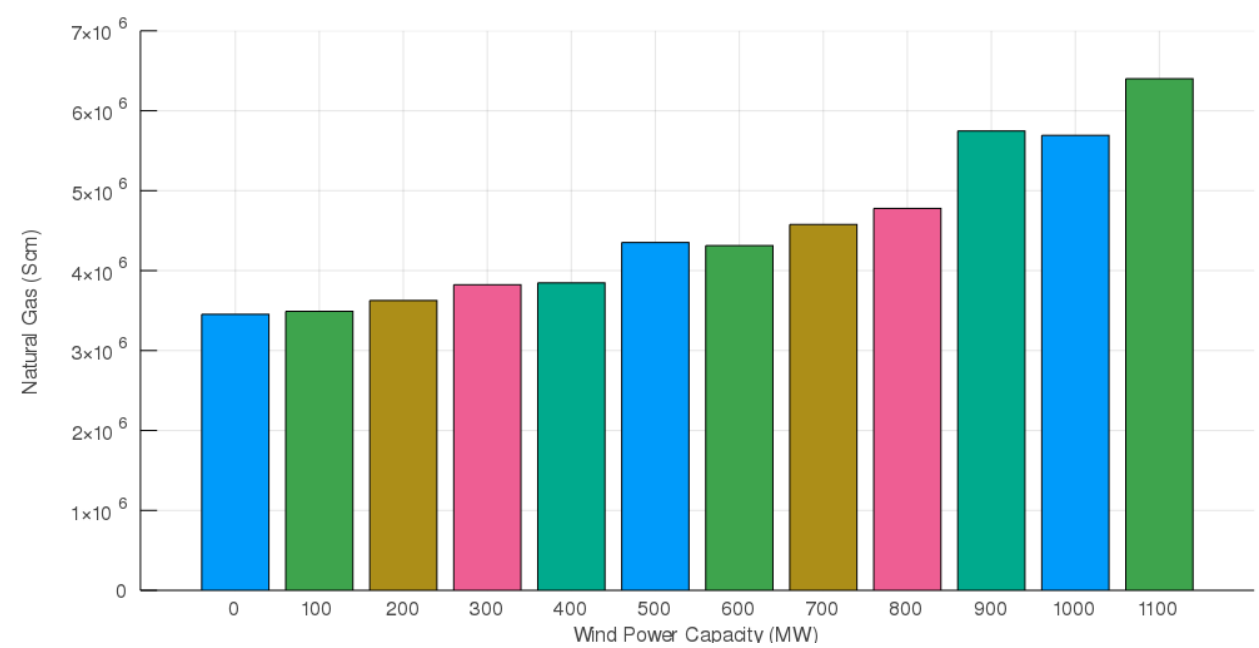

Figure 3. Total gas requirements for installed wind power capacities 
As mentioned above, one of the points to consider were the technical requirements of the gas fired thermal generators, specifically in this case the up and down ramps. These ramps become critical to an intermittent renewable energy source, such as wind power. In cases such as this one, the ramps of the coal-fired generators are very limited, leaving the task of controlling the intermittent to the gas-fired generators. However, the ramps of the gas generators, have their restrictions, and the value of these is intrinsic to the generator, which means that the limits designed for the generator cannot be exceeded or changed [13].

Therefore, when including wind power generation, the limits of up and down ramps must be known, especially those of the gas fired power plants. That is why the ramps were determined both up and down, for a period of 192 hours, for three cases of installed wind capacity ( $0 \mathrm{MW}, 500 \mathrm{MW}$ and $1000 \mathrm{MW})$, as shown in Figure 4. The ramps were calculated by the hourly difference of the power generated by all the gas fired thermal generators, i.e. the values of the ramps are not from a single generator, on the contrary they are the sum of the ramps required from all the gas fired generators, at the same instant of time.

In Figure 4, it can be seen how the growth in installed wind capacity leads to an increase in the technical requirements of gas fired boilers, in this case the ramps. Note that the growth is in the absolute value of the ramps, ie is given both in the up and down ramps. In the case where there is no wind power generation, the critical values of the up and down ramps are $332 \mathrm{MW} / \mathrm{h}$ and $159 \mathrm{MW} / \mathrm{h}$ respectively. For the case of $500 \mathrm{MW}$ of installed wind capacity, the critical values of the up and down ramps are 1.3 and 2 times higher than the case of $0 \mathrm{MW}$ respectively. And for the case of $1000 \mathrm{MW}$ of installed wind capacity, the critical values of the up and down ramps are 2.1 and 3.3 times higher than the initial case respectively.

Whereas the values of the up and down ramps of a gas fired thermal generator tend to be the same, only the peak values of the ramps can be taken. Hence, for the implementation of $500 \mathrm{MW}$ of wind power generation, the critical values of the ramps are increased by $26 \%$. Under normal conditions, the ramps required by thermal generators do not reach their limits, thus it is not necessary to make major changes to the system to achieve these target ramps. Nonetheless, in the case of implementing $1000 \mathrm{MW}$ of wind power generation, the critical values of the ramps are increased by $108 \%$ with respect to the initial case. Therefore, it is necessary to double the number of ramps that are currently available, which generates the need for the implementation of another thermal gas generator, with certain technical requirements, to achieve these target ramps.

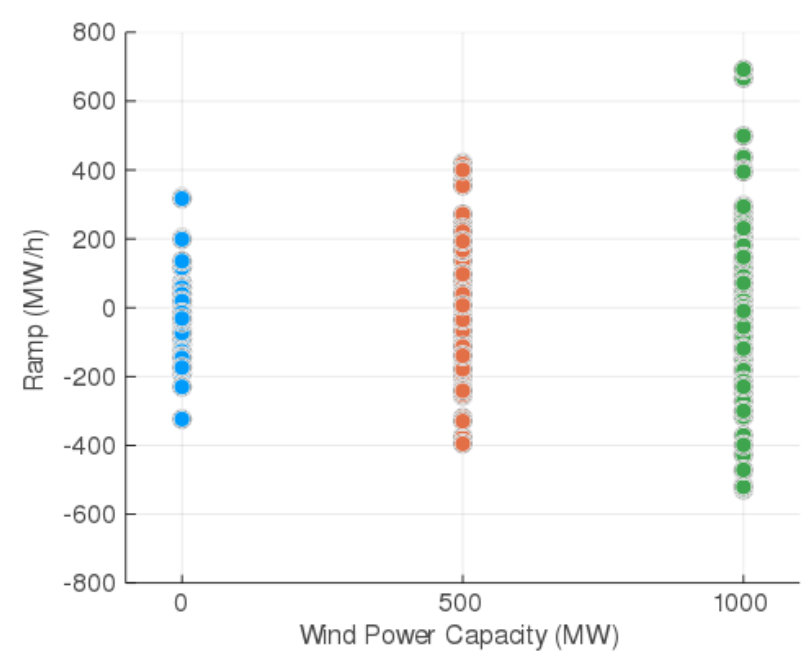

Figure 4. Gas network linkage with electricity network

\section{CONCLUSION}

Global energy sources are being transitioned by reducing the consumption of fossil fuels and replacing them with renewable resources, in an effort to reduce greenhouse gas emissions. In contrast, it is necessary to incorporate natural gas into the energy transition discourse in order to meet the operational, economic, political and social needs of the countries. In this paper, a detailed model of an economic dispatch for a 24-bus electric system interconnected with a 20 node natural gas network, that involves wind energy was presented under several operational settings for a 24-hour time frame. It was demonstrated that the planning process 
required between the NG infrastructure and the power system can be achieved through the mathematical model presented.

Due to the uncertainty and unpredictability associated with renewable resources and the limited technical characteristics of coal-fired generators, then the gas will play a role in the energy transition. This leads to a greater need for gas and gas-fired generators, regardless of the fact that the cost of generating energy from these is higher than for coal-fired ones. The flexibility of both the power and gas systems is vital for the implementation of renewable energy sources. Furthermore, this flexibility is limited and costly. Consequently, the excessive increase in the use of renewable energies can cause the system to reach its operational limits, without achieving optimal results, and it is necessary to make technical changes in the system. Examples of these changes include the implementation of new gas-fired power plants, new transmission lines, greater availability of gas, and new gas transportation tubes.

\section{ACKNOWLEDGEMENT}

Colombia.

The authors gratefully acknowledge the support of the Universidad Autónoma de Occidente in Cali,

\section{REFERENCES}

[1] H. Chuan, L. Tianqi, W. Lei, and M. Shahidehpour, "Robust coordination of interdependent electricity and natural gas systems in day-ahead scheduling for facilitating volatile renewable generations via power-to-gas technology,” Journal of Modern Power Systems and Clean Energy, vol. 5, no. 3, pp. 375-388, 2017, doi: 10.1007/s40565-017-0278-z.

[2] T. Li, M. Eremia, and M. Shahidehpour, "Interdependency of natural gas network and power system security," IEEE Transactions on Power Systems, vol. 23, no. 4, pp. 1817-1824, 2008, doi: 10.1109/TPWRS.2008.2004739.

[3] A. Street, L. A. Barroso, R. Chabar, A. T. Mendes, and M. V. Pereira, "Pricing flexible natural gas supply contracts under uncertainty in hydrothermal markets," IEEE Transactions on Power Systems, vol. 23, no. 3, pp. 1009-1017, 2008, doi: 10.1109/TPWRS.2008.926442.

[4] A. Zubair, A. A. Tanvir, and M. M. Hasan, "Optimal planning of standalone solar-wind-diesel hybrid energy system for a coastal area of bangladesh," International Journal of Electrical and Computer Engineering (IJECE), vol. 2, no. 6, pp. 731-738, 2012.

[5] A. Foley and A. G. Olabi, "Renewable energy technology developments, trends and policy implications that can underpin the drive for global climate change," Renewable and Sustainable Energy Reviews, vol. 68, Feb, 2017, doi: 10.1016/j.rser.2016.12.065.

[6] J. Restrepo-Trujillo, R. Moreno-Chuquen, and F. N. Jiménez-Garc 1a, "Strategies of expansion for electric power systems based on hydroelectric plants in the context of climate change: Case of analysis of colombia," International Journal of Energy Economics and Policy (IJEEP), vol. 10, no. 6, pp. 66-74, 2020, doi: 10.32479/ijeep.9813.

[7] O. Ellabban, H. Abu-Rub, and F. Blaabjerg, "Renewable energy resources: Current status, future prospects and their enabling technology," Renewable and Sustainable Energy Reviews, vol. 39, pp. 748-764, 2014, doi: 10.1016/j.rser.2014.07.113.

[8] I. E. Agency, Renewables Information 2019. OECD Publishing, 2019. [Online]. Available: https://www.oecdilibrary.org/content/publication/fa89fd56-en.

[9] S. S. Sakthi, R. Santhi, N. M. Krishnan, S. Ganesan, and S. Subramanian, "Wind integrated thermal unit commitment solution using grey wolf optimizer," International Journal of Electrical and Computer Engineering (IJECE), vol. 7, no. 5, pp. 2309-2320, 2017, doi: 10.11591/ijece.v7i5.pp2309-2320.

[10] R. Moreno and O. Florez, "Online dynamic assessment of system stability in power systems using the unscented kalman filter," International Review of Electrical Engineering (IREE), vol. 14, no. 6, 2019.

[11] L. E. Jones, Renewable energy integration: practical management of variability, uncertainty, and flexibility in power grids. Academic Press, 2017.

[12] S. Cantillo and R. Moreno, "Power system operation considering detailed modelling of energy storage systems," International Journal of Electrical and Computer Engineering (IJECE), vol. 11, no. 1, pp. 182-200. 2021.

[13] J. Hentschel, U. Babi c, and H. Spliethoff, "A parametric approach for the valuation of power plant flexibility options," Energy Reports, vol. 2, pp. 40-47, 2016, doi: 10.1016/j.egyr.2016.03.002.

[14] M. Panto s, "Market-based congestion management in electric power systems with increased share of natural gas dependent power plants," Energy, vol. 36, no. 7, pp. 4244-4255, 2011, doi: 10.1016/j.energy.2011.04.019.

[15] A. Soroudi, Power System Optimization Modeling in GAMS. Springer, Aug 2017.

[16] S.-C. Kim and S. R. Salkut, "Optimal power flow based congestion management using enhanced genetic algorithms," International Journal of Electrical and Computer Engineering (IJECE), vol. 9, no. 2, pp. 875-883, 2019, doi: 10.11591/ijece.v9i2.pp875-883. 
[17] R. Moreno-Chuquen and S. Cantillo-Luna, "Assessment of a multiperiod optimal power flow for power system operation," International Review of Electrical Engineering (IREE), vol. 15, no. 6, pp. 484-492, 2020, doi: 10.15866/iree.v15i6.18304.

[18] C. Boonchuay, K. Tomsovic, F. Li, and W. Ongsakul, "Robust optimization-based DC optimal power flow for managing wind generation uncertainty," in AIP Conference Proceedings, vol. 1499, no. 1, 2012, pp. 31-35, doi: $10.1063 / 1.4768966$.

[19] R. A. Jabr, "Adjustable robust OPF with renewable energy sources," IEEE Transactions on Power Systems, vol. 28, no. 4, pp. 4742-4751, Nov 2013, doi: 10.1109/TPWRS.2013.2275013.

[20] R. Moreno, J. Obando, and G. Gonzalez, "An integrated opf dispatching model with wind power and demand response for day-ahead markets," International Journal of Electrical and Computer Engineering (IJECE), vol. 9, no. 4, pp. 2794-2802, 2019, doi: 10.11591/ijece.v9i4.pp2794-2802.

[21] J. S. Obando, G. González, and R. Moreno, "Quantification of operating reserves with high penetration of wind power considering extreme values," International Journal of Electrical and Computer Engineering (IJECE), vol. 10, no. 2, pp. 1693-1700, 2020, doi: 10.11591/ijece.v10i2.pp1693-1700.

[22] D. De Wolf and Y. Smeers, "The gas transmission problem solved by an extension of the simplex algorithm," Management Science, vol. 46, no. 11, pp. 1454-1465, 2000, doi: 10.1287/mnsc.46.11.1454.12087.

[23] A. Martin, M. Möller, and S. Moritz, "Mixed integer models for the stationary case of gas network opti- mization," Mathematical programming, vol. 105, no. 2-3, pp. 563-582, 2006, doi: 10.1007/s10107-005-0665-5.

[24] M. E. Pfetsch et al., "Validation of nominations in gas network optimization: models, methods, and solutions," Optimization Methods and Software, vol. 30, no. 1, pp. 15-53, 2015, doi: 10.1080/10556788.2014.888426.

[25] X. Zhang, M. Shahidehpour, A. Alabdulwahab, and A. Abusorrah, "Hourly electricity demand response in the stochastic day-ahead scheduling of coordinated electricity and natural gas networks," IEEE Transactions on Power Systems, vol. 31, no. 1, pp. 592-601, 2015, doi: 10.1109/TPWRS.2015.2390632.

[26] C. Unsihuay, J. Marangon-Lima, and A. Z. De Souza, "Short-term operation planning of integrated hydrothermal and natural gas systems," in 2007 IEEE Lausanne Power Tech. IEEE, 2007, pp. 1410-1416, doi: 10.1109/PCT.2007.4538522.

[27] C. Liu, M. Shahidehpour, Y. Fu, and Z. Li, "Security-constrained unit commitment with natural gas transmission constraints," IEEE Transactions on Power Systems, vol. 24, no. 3, pp. 1523-1536, 2009, doi: 10.1109/TPWRS.2009.2023262.

[28] A. Martinez-Mares and C. R. Fuerte-Esquivel, "A unified gas and power flow analysis in natural gas and electricity coupled networks," IEEE Transactions on Power Systems, vol. 27, no. 4, pp. 2156-2166, 2012, doi: 10.1109/TPWRS.2012.2191984.

[29] M. Qadrdan, M. Chaudry, J. Wu, N. Jenkins, and J. Ekanayake, "Impact of a large penetration of wind generation on the gb gas network," Energy Policy, vol. 38, no. 10, pp. 5684-5695, 2010, doi: 10.1016/j.enpol.2010.05.016.

[30] M. Qadrdan, J. Wu, N. Jenkins, and J. Ekanayake, "Operating strategies for a gb integrated gas and elec- tricity network considering the uncertainty in wind power forecasts," IEEE Transactions on Sustainable Energy, vol. 5, no. 1, pp. 128-138, 2013, doi: 10.1109/TSTE.2013.2274818.

[31] M. Qadrdan, M. Abeysekera, M. Chaudry, J. Wu, and N. Jenkins, "Role of power-to-gas in an integrated gas and electricity system in great britain," International Journal of Hydrogen Energy, vol. 40, no. 17, pp. 5763-5775, 2015, doi: 10.1016/j.ijhydene.2015.03.004.

[32] F. Sohrabi, F. Jabari, B. Mohammadi-Ivatloo, and A. Soroudi, "Coordination of interdependent natural gas and electricity systems based on information gap decision theory," IET Generation, Transmission and Distribution, vol. 13, no. 15, pp. 3362-3369, 2019, doi: 10.1049/iet-gtd.2018.6895.

[33] X. Zhang, L. Che, and M. Shahidehpour, "Impact of natural gas system on short-term scheduling with volatile renewable energy," in 2015 IEEE Power and Energy Society General Meeting, 2015, pp. 1-5, doi: 10.1109/PESGM.2015.7285633.

[34] L. Bai, F. Li, H. Cui, T. Jiang, H. Sun, and J. Zhu, "Interval optimization based operating strategy for gas-electricity integrated energy systems considering demand response and wind uncertainty," Applied energy, vol. 167, pp. 270-279, 2016, doi: 10.1016/j.apenergy.2015.10.119.

[35] I. Dunning, J. Huchette, and M. Lubin, “Jump: A modeling language for mathematical optimization,” SIAM Review, vol. 59, no. 2, pp. 295-320, 2017, doi: 10.1137/15M1020575. 